\title{
Screen time and adiposity in adolescents in Mexico
}

\author{
Martín Lajous ${ }^{1,2}$, Jorge Chavarro ${ }^{2,3}$, Karen E Peterson ${ }^{3,4}$, Bernardo Hernández-Prado ${ }^{\text {, }}$ \\ Aurelio Cruz-Valdéz ${ }^{1}$, Mauricio Hernández-Ávila ${ }^{1}$ and Eduardo Lazcano-Ponce ${ }^{1, *}$ \\ ${ }^{1}$ Center for Population Health Research, National Institute of Public Health, Av. Universidad 655, Col. Santa \\ Maria Ahuacatitlán, CP 62508, Cuernavaca, Morelos, Mexico: ${ }^{2}$ Department of Epidemiology, Harvard School \\ of Public Health, Boston, MA, USA: ${ }^{3}$ Department of Nutrition, Harvard School of Public Health, Boston, MA, \\ USA: ${ }^{4}$ Department of Society, Human Development and Health, Harvard School of Public Health, Boston, MA, USA
}

Submitted 22 November 2007: Accepted 18 November 2008: First published online 23 February 2009

\begin{abstract}
Objective: To assess the association of time spent viewing television, videos and video games with measures of fat mass (BMI) and distribution (triceps and subscapular skinfold thicknesses (TSF, SSF)).

Design: Cross-sectional validated survey, self-administered to students to assess screen time (television, videos and video games) and lifestyle variables. Trained personnel obtained anthropometry. The association of screen time with fat mass and distribution, stratified by sex, was modelled with multivariable linear regression analysis, adjusting for potential confounders and correlation of observations within schools.

Setting: State of Morelos, Mexico.

Subjects: Males ( $n$ 3519) and females ( $n$ 5613) aged 11 to 18 years attending urban and rural schools in Morelos.

Results: In males, screen time of $>5 \mathrm{~h} / \mathrm{d}$ compared with $<2 \mathrm{~h} / \mathrm{d}$ was significantly associated with a $0 \cdot 13(95 \%$ CI 0 04, 0 23) higher BMI Z-score, $0 \cdot 73 \mathrm{~mm}(95 \% \mathrm{CI} 0 \cdot 24$, $1 \cdot 22)$ higher SSF and $1 \cdot 08 \mathrm{~mm}(95 \%$ CI $0 \cdot 36,1 \cdot 81)$ higher TSF. The positive association of screen time with SSF was strongest in males aged 11-12 years. Sexual maturity appeared to modify the association in females; a positive association between screen time and SSF was observed in those who had not undergone menarche ( $P$ for trend $=0 \cdot 04$ ) but not among sexually mature females ( $P$ for trend $=0 \cdot 75$ ).

Conclusion: Screen time is associated with fat mass and distribution among adolescent males in Mexico. Maturational tempo appears to affect the relationship of screen time with adiposity in boys and girls. Findings suggest that obesity preventive interventions in the Mexican context should explore strategies to reduce screen time among youths in early adolescence.
\end{abstract}

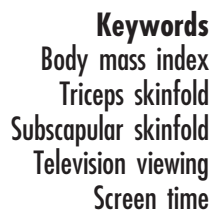

ody mass index Triceps skinfold ubscapular skinfold Screen time
Consistent with worldwide trends, the prevalence of obesity in Mexico is increasing ${ }^{(1)}$. Between 1999 and 2006 , the proportion of adults who were overweight or obese increased from 67 to $72 \%$ in women and from 61 to $67 \%$ in men ${ }^{(2,3)}$. Using international cut-off points, the prevalence of obesity in 1999 was $5.5 \%$ in pre-school children and $19 \cdot 5 \%$ in children aged 5 to 11 years ${ }^{(4)}$.

Understanding behavioural determinants of youth obesity trends is essential to developing effective public health approaches to prevention and control in different country contexts. In observational studies, television viewing in children and adolescents has been associated with increased adiposity and obesity ${ }^{(5-9)}$ and predicted high BMI, smoking, low cardiorespiratory fitness and high serum cholesterol in early adulthood ${ }^{(10)}$. Randomized trials to limit television time and computer use among children in the USA resulted in a significant reduction of
$\mathrm{BMI}^{(11)}$ and lower BMI, triceps skinfold thickness (TSF), waist circumference and waist:hip ratio ${ }^{(12)}$. Decreases in television viewing also mediated the effect of a middleschool, interdisciplinary curriculum on obesity (classified as BMI and TSF $>85$ th percentile) in young adolescent $\operatorname{girls}^{(13)}$.

Previous studies of the association of screen time with youth obesity have inconsistently assessed the use of media other than television. Limited information on demographic, lifestyle and reproductive factors for chronic disease also may undermine the interpretability of results due to confounding by unmeasured variables. Furthermore, assessment of fat distribution in early puberty through skinfold thickness in addition to fat mass may unveil additional insights on chronic disease risk in Mexican youths. In the present study, we examined the association between time spent viewing television, videos 
and video games and anthropometric measures of fat mass and distribution in a large survey of adolescents in the State of Morelos in Mexico.

\section{Research methods and procedures}

\section{Study population}

The data presented here derive from a large, representative survey conducted in 1999 to assess the prevalence of chronic disease risk factors in youths in the State of Morelos, Mexico. The methods are described elsewhere ${ }^{(14)}$. Briefly, the study included a sample of youths aged 11 to 24 years attending public junior high schools, high schools and the State university. The sampling unit was the school. The study population comprised 13293 individuals, 56\% of whom were female. The response rate was 98.6\%. An imbalance between males and females in the sample was due to both an underlying distribution that favours females and a higher response rate in this group. Signed informed consent forms were obtained separately from the study participants and from their parents prior to collection of information. Participants were asked to complete a selfadministered questionnaire on general lifestyle, frequency of food consumption, physical activity, drug use and health-care use. The survey was conducted in classrooms during school hours; anthropometry on all participants was obtained by trained staff in school settings. The study was approved by the Human Subjects Committee of the National Institute of Public Health of Mexico.

Eligible individuals for the current analysis were 11 to 18 years of age with complete questionnaire and anthropometric information. We excluded young adults between 19 and 24 years of age because we considered adolescence the developmental stage most biologically relevant to the emergence of chronic disease in early adulthood. To reduce potential confounding by underlying conditions associated with disability and related inactivity, we excluded underweight individuals, defined as being below the 15th percentile for $\mathrm{BMI}^{(15)}$ and for $\operatorname{TSF}^{(16,17)}$. The final analytic sample comprised 9132 participants, $62 \%$ of whom were female. This sub-sample did not differ significantly from the original sample with respect to major sociodemographic characteristics.

\section{Data collection}

Screen viewing and physical activity were measured using a questionnaire validated in Mexican youths ${ }^{(18)}$. Individuals were asked about their usual daily hours viewing television, videos and video games (never, $<1$, $1-2,2-3,3-4,4-5,6-7$ or $>7$ ) on weekdays, Saturdays and Sundays. Computer use was not collected because home computer use is uncommon in this population. Eighteen per cent of participants reported total daily screen time greater than $12 \mathrm{~h}$. A weighted average of hours of screen viewing (weekdays, Saturday and Sunday) was computed to obtain an overall average screen time. We categorized screen time as $<2,2-2 \cdot 9,3-3 \cdot 9,4-4 \cdot 9$ and $\geq 5 \mathrm{~h} / \mathrm{d}$ in order to limit the error introduced by multitasking (e.g. playing video games while watching television) and the influence of outliers. Total television and total video/video games were similarly categorized. A weighted average of hours of inactivity was calculated using weekday and weekend hours of sitting down, using private or public transportation, doing homework and sleeping. The questionnaire also included eleven items to evaluate weekly hours of recreational physical activities (never, $<0 \cdot 5,0 \cdot 5-2,2-4$ and $4-6)^{(17)}$. Weekly expenditure of metabolic equivalents (MET) of moderate and vigorous physical activity was estimated by multiplying the responses to questions by the activity-specific energy expenditure as reported by Ainsworth et al. ${ }^{(19)}$. Energy intake was estimated from a 103-item FFQ adapted from a questionnaire validated for the Mexican adult population $^{(20)}$. Socio-economic status (SES) was assessed using an index derived from a principal components analysis for the Mexican population that includes number of rooms in the house, people living in the household, municipal services, sanitary conditions, educational level of the mother's most recent sexual partner, and ownership of home, car, television, video recorder and telephone. Three categories were constructed using tertiles of the principal component score ${ }^{(21)}$.

Height, weight, TSF and subscapular skinfold thickness (SSF) were measured using standardized procedures by trained personnel. Height and weight were measured using daily gauged portable stadiometers and portable Tanita scales (Tanita Corp., Itabashini-Ku, Tokyo, Japan), respectively. For skinfolds, the average of three measurements using Lange callipers (Beta Technology, Inc., Santa Cruz, CA, USA) was used and expressed in millimetres. BMI was calculated as weight $/$ height $^{2}\left(\mathrm{~kg} / \mathrm{m}^{2}\right)$ using the measured anthropometric data. Age- and sexspecific standard deviation scores ( $Z$-scores) for BMI were calculated using the 2000 guidelines of the Centers for Disease Control and Prevention ${ }^{(15)}$. The age-specific cutoff points for overweight and obesity of the International Obesity Taskforce were used to estimate their prevalence. These cut-off points use an international reference population comprising children and adolescents from six different countries ${ }^{(22)}$. These cut-offs were used for descriptive purposes only, to permit comparisons of BMI distribution with other countries.

\section{Statistical analysis}

We analysed females and males separately. Means and standard deviations were estimated for screen viewing time within categories of selected participant characteristics and the distribution was compared across categories with the Kruskal-Wallis test. For ordinal predictors, we tested for linearity using linear regression. Next, we constructed linear regression models to explore the 
Table 1 Characteristics of 9132 Mexican adolescents from public schools in Morelos, Mexico (1999)

\begin{tabular}{|c|c|c|c|c|}
\hline \multirow[b]{2}{*}{ Variable } & \multicolumn{2}{|c|}{ Males ( $n$ 3519) } & \multicolumn{2}{|c|}{ Females ( $n$ 5613) } \\
\hline & Mean & SD & Mean & SD \\
\hline Age (years) & $13 \cdot 8$ & $1 \cdot 8$ & $13 \cdot 9$ & $1 \cdot 7$ \\
\hline $\begin{array}{l}\text { Energy intake }(\mathrm{kJ} / \mathrm{d}) \\
\text { Moderate-to-vigorous physical activity (MET/week) } \\
\text { Total screen time }{ }^{*}(\mathrm{~h} / \mathrm{d})\end{array}$ & $\begin{array}{r}17975 \\
110 \\
5 \cdot 9\end{array}$ & $\begin{array}{r}5306 \\
42 \\
3 \cdot 0\end{array}$ & $\begin{array}{r}16670 \\
90 \cdot 8 \\
5 \cdot 4\end{array}$ & $\begin{array}{r}5332 \\
47 \cdot 3 \\
3 \cdot 0\end{array}$ \\
\hline $\begin{array}{l}\text { BMI (Z-score) } \\
\text { Triceps skinfold thickness }(\mathrm{mm}) \\
\text { Subscapular skinfold thickness }(\mathrm{mm})\end{array}$ & $\begin{array}{l}0 \cdot 48 \\
14 \\
11\end{array}$ & $\begin{array}{l}0 \cdot 97 \\
7 \\
5\end{array}$ & $\begin{array}{l}0 \cdot 58 \\
22 \\
15\end{array}$ & $\begin{array}{l}0 \cdot 84 \\
7 \\
5\end{array}$ \\
\hline $\begin{array}{l}\text { Obesityt (\%) } \\
\text { Overweightt (\%) } \\
\text { Mean age at menarche (years) }\end{array}$ & \multicolumn{2}{|c|}{$\begin{array}{r}6 \cdot 7 \\
30 \cdot 0\end{array}$} & \multicolumn{2}{|c|}{$\begin{array}{r}6.0 \\
30.5\end{array}$} \\
\hline
\end{tabular}

MET, metabolic equivalents.

${ }^{*}$ Average daily hours of viewing television, videos and video games combined.

tInternational Obesity Taskforce cut-off points for BMI for age and sex ${ }^{(22)}$.

association of BMI $Z$-scores, TSF and SSF with screen time using the SAS SURVEYREG procedure to account for the non-independence of the observations given that the primary sampling unit was the school and that observations within schools may be correlated (SAS version 8; SAS Institute Inc., Cary, NC, USA). Potential confounders of these associations considered in the multivariable model included age, height, SES tertile, single-parent family, birth in a hospital, father's educational level, mother's educational level, family income, family health insurance, weekly MET of moderate-to-vigorous physical activity, daily hours of inactivity excluding screen time, type of community (urban, suburban, rural), total energy intake, diagnosis of asthma, dieting and frequency of restaurant dining. Given the rapid change in adipose tissue distribution, linear growth, metabolic and hormonal environment during adolescence, we hypothesized that age would modify the relationship of screen time with adiposity. Based on the results of this analysis we considered post hoc sexual maturity as another potential effect modifier. Sexual maturity was also considered a confounder. Females who had undergone menarche and males who reported having had an ejaculation were considered sexually mature. We also considered living in a rural environment and moderate-to-vigorous physical activity to be modifiers of this relationship because physical activity affects adipose tissue and individuals in a rural environment may be more active. Results are presented as age-adjusted and multivariate-adjusted.

\section{Results}

Table 1 shows the characteristics of the study population. Male adolescents reported a higher energy intake and greater MET of moderate and vigorous physical activities than females. After transforming questionnaire categories on media use to continuous variables, among males, a
Table 2 Daily hours of television, video and video game use by sociodemographic characteristics of Mexican adolescents from public schools in Morelos, Mexico (1999)

\begin{tabular}{|c|c|c|c|c|}
\hline \multirow[b]{2}{*}{ Variable } & \multicolumn{2}{|c|}{ Males } & \multicolumn{2}{|c|}{ Females } \\
\hline & Mean & SD & Mean & $S D$ \\
\hline \multicolumn{5}{|l|}{ Age (years) } \\
\hline $11-12$ & $5 \cdot 9$ & $2 \cdot 9$ & $5 \cdot 6$ & $3 \cdot 0$ \\
\hline $13-14$ & $5 \cdot 7$ & $3 \cdot 1$ & $5 \cdot 3$ & $3 \cdot 0$ \\
\hline $15-16$ & $6 \cdot 0$ & $2 \cdot 9$ & $4 \cdot 7$ & $2 \cdot 9$ \\
\hline $17-18$ & $6 \cdot 6$ & $2 \cdot 7$ & $6 \cdot 1$ & $3 \cdot 0$ \\
\hline \multicolumn{5}{|l|}{ Community type } \\
\hline Rural & $5 \cdot 3$ & $3 \cdot 1$ & $5 \cdot 1$ & $3 \cdot 0$ \\
\hline Suburban & 5.9 & $2 \cdot 9$ & 4.9 & $3 \cdot 0$ \\
\hline Urban & $6 \cdot 6$ & $2 \cdot 8$ & $6 \cdot 1$ & $2 \cdot 9$ \\
\hline \multicolumn{5}{|l|}{ Socio-economic status } \\
\hline Low & $6 \cdot 2$ & $2 \cdot 9$ & $5 \cdot 1$ & $3 \cdot 1$ \\
\hline Medium & $5 \cdot 3$ & $3 \cdot 1$ & $5 \cdot 2$ & $3 \cdot 0$ \\
\hline High & $6 \cdot 6$ & $2 \cdot 7$ & $5 \cdot 8$ & $2 \cdot 9$ \\
\hline \multicolumn{5}{|l|}{ Medical insurance } \\
\hline Uninsured & $6 \cdot 2$ & $2 \cdot 9$ & $5 \cdot 5$ & $3 \cdot 0$ \\
\hline Insured & $5 \cdot 7$ & $3 \cdot 0$ & $5 \cdot 3$ & $3 \cdot 0$ \\
\hline \multicolumn{5}{|l|}{ Dieting } \\
\hline To lose weight & $6 \cdot 1$ & $3 \cdot 1$ & $5 \cdot 0$ & $3 \cdot 0$ \\
\hline To gain weight & $6 \cdot 1$ & $3 \cdot 1$ & $6 \cdot 2$ & $2 \cdot 8$ \\
\hline Not on a special diet & $5 \cdot 9$ & $3 \cdot 0$ & $5 \cdot 4$ & $3 \cdot 0$ \\
\hline
\end{tabular}

greater amount of total daily hours of screen time was spent watching television $(2 \cdot 7(\mathrm{SD} 1.9) \mathrm{h})$ than watching videos (1.9 (SD 1.8) h) and playing video games (1.8 (SD $1 \cdot 9) \mathrm{h}$ ). On average, females spent $2 \cdot 8$ (sD $1 \cdot 9$ ) h watching television, $1.6(\mathrm{SD} 1 \cdot 8) \mathrm{h}$ on videos and $1.3(\mathrm{SD} 1 \cdot 8) \mathrm{h}$ playing video games every day. Menarche was reported by $5229(93 \cdot 2 \%)$ of female participants. The prevalence of obesity was slightly higher in males; approximately one-third of males and females were overweight.

Total daily screen time by different sociodemographic characteristics is described in Table 2. Significant differences in the mean daily screen time were observed for age, type of community, SES and medical insurance in males and females $(P<0 \cdot 01)$. Adolescent girls who reported they were dieting to lose weight reported significantly less screen time 
than those who said they wanted to gain weight. Mean screen time increased significantly with the level of urbanicity and, in females, screen time increased with increasing SES $(P<0 \cdot 01)$. Energy intake increased significantly with increasing screen time in males and females $(P<0 \cdot 001)$. The mean daily energy intake in males was $15305 \mathrm{~kJ}$ for $<2 \mathrm{~h}$ of screen time/d and $18759 \mathrm{~kJ}$ for $>5 \mathrm{~h} / \mathrm{d}$. Females had a mean daily energy intake of $15166 \mathrm{~kJ}$ for $<2 \mathrm{~h}$ of screen time $/ \mathrm{d}$ and $17581 \mathrm{~kJ}$ for $>5 \mathrm{~h} / \mathrm{d}$.

In males, screen time was positively related to BMI $Z$-score in age-adjusted and multivariate-adjusted analyses. In the multivariate-adjusted model, males with $>5 \mathrm{~h}$ screen time/d had a $0 \cdot 13(95 \%$ CI $0 \cdot 04,0 \cdot 23)$ higher BMI $Z$-score compared with males with $<2 \mathrm{~h} / \mathrm{d}$ ( $P$ for trend $<0 \cdot 003)$. In females, screen time was positively related with BMI $Z$-score in age-adjusted analyses but not in multivariate-adjusted analyses (Table 3).

Screen time was positively related to TSF and SSF in males. After adjusting for confounding variables, males with $>5 \mathrm{~h}$ of screen time/d had a $1.08 \mathrm{~mm}$ (95\% CI $0 \cdot 36$, $1 \cdot 81)$ greater TSF compared with males reporting $<2 \mathrm{~h} / \mathrm{d}$ ( $P$ for trend $=0 \cdot 01$ ). Similarly, after adjusting for confounding variables, males with $>5 \mathrm{~h}$ of screen time/d had a $0.73 \mathrm{~mm}(95 \% \mathrm{CI} 0 \cdot 24,1 \cdot 22)$ greater SSF compared with males with $<2 \mathrm{~h} / \mathrm{d}$ ( $P$ for trend $=0 \cdot 006$ ). In females, screen time was positively related to TSF and SSF in ageadjusted but not multivariate-adjusted analyses.

Age did not modify the association between screen time and BMI $Z$-score or TSF in males or females. Nevertheless, the association between screen time and SSF differed significantly by age categories in males ( $P$ interaction $=0 \cdot 005$ ) A significant linear trend of increasing SSF with greater screen time was found in younger but not older males (Fig. 1). In females, age did not modify the association between screen time and SSF. The association was however modified by sexual maturity; screen time was positively related to SSF among females who had not undergone menarche $(P$ for trend $=0.04)$ but not among sexually mature females ( $P$ for trend $=0 \cdot 75$; Fig. 2 ).

Males spent $54 \%$ of their screen time on videos and video games, while females spent $48 \%$. For males, we found a significant increasing trend only in BMI Z-score when we analysed videos and video games independently of television $(P=0.03)$. No association with television by itself was found. In females, no associations were observed when television and videos/video games were analysed independently.

\section{Discussion}

The present study evaluated the association between time spent viewing television, videos and video games and measures of fat mass and distribution in a large survey of Mexican adolescents in the State of Morelos. In males, BMI $Z$-score, TSF and SSF were directly associated with

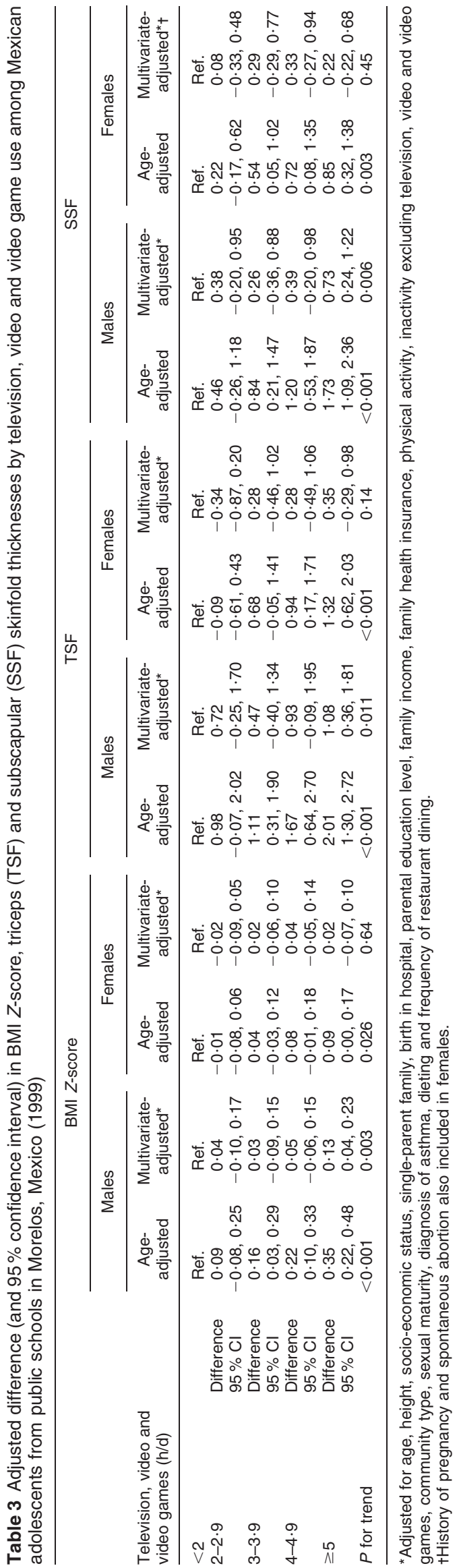




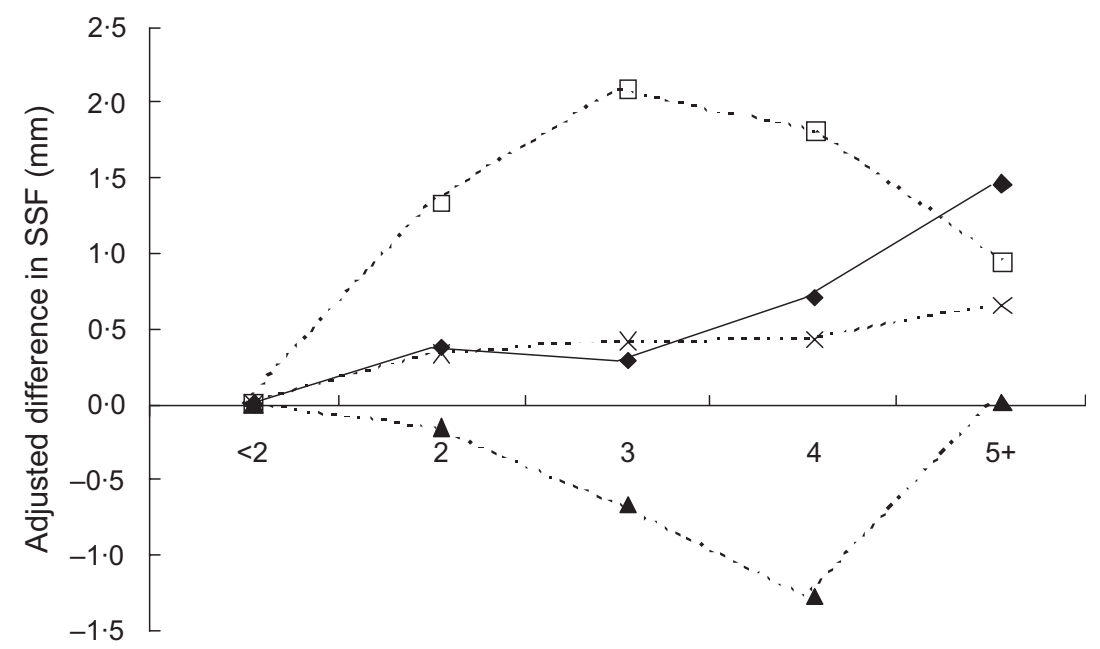

Total daily screen time $(h)$

Fig. 1 Adjusted difference in subscapular skinfold thickness (SSF, mm) with total daily screen time (h) by age group ( $-\downarrow-$, 11-12 years; - - $\times$ - -, 13-14 years; - - $\boldsymbol{\Delta}$ - -, 15-16 years; - - $\square$ - -, 17-18 years) in Mexican male adolescents from public schools in Morelos, Mexico (1999)

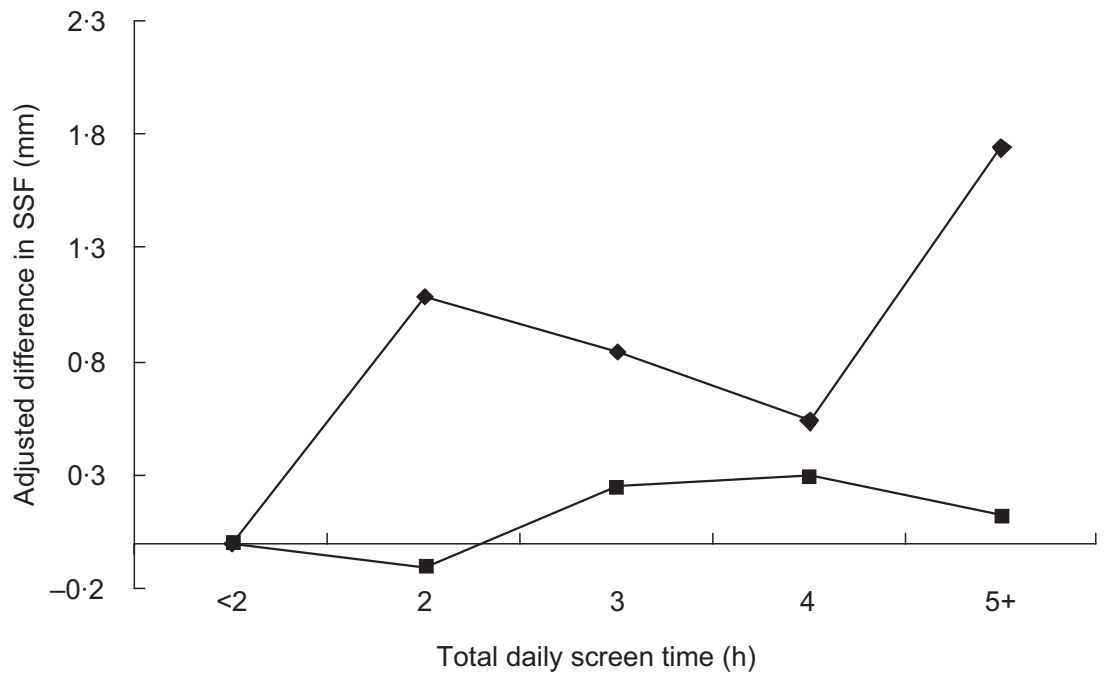

Fig. 2 Adjusted difference in subscapular skinfold thickness (SSF, mm) with total daily screen time (h) by sexual maturity (- - , premenarcheal; _ _ - postmenarcheal) in Mexican female adolescents from public schools in Morelos, Mexico (1999)

time spent viewing television, videos and video games. The association of screen time with SSF seemed to be stronger in 11- and 12-year-old males compared with older youths. Conversely, no overall association of screen time and anthropometric measures was observed among Mexican female adolescents. An association between SSF thickness and screen time was observed in sexually immature females.

Our results are consistent with previous cross-sectional and longitudinal findings on television viewing and increased adiposity and obesity in Mexican and other populations ${ }^{(5-9,23-30)}$. Nevertheless, others have reported weak or no associations between television viewing and physical inactivity and adiposity ${ }^{(31-34)}$. Disparate results may be explained in part by differences in the age distribution of participants, the cross-sectional nature of some studies and the use of less comprehensive measures of media use. Nevertheless, two randomized controlled trials of interventions that reduced television and computer use lend strong support to a causal relationship between screen time and increased adiposity in younger children ${ }^{(11,12)}$. Moreover, a recent analysis on the combined influence of not meeting the current physical activity and screen time recommendations of 11000-13000 pedometer steps/d and $<2 \mathrm{~h} / \mathrm{d}$ found that overweight children were more likely to be non-compliant with these recommendations ${ }^{(35)}$.

There are several indications that screen time plays a different role within age and sex groups due to differences 
in the tempo of physical development. Most studies where the link between screen time and increased adiposity or obesity was found included children younger than 10 years of age ${ }^{(7-9,11,12,25,28-30)}$. Studies that did not find the association had a mean age closer to 13 years ${ }^{(31-34)}$. In the current study, age did not appear to modify the association between screen time and BMI and TSF. However, screen time was directly associated with SSF among 11- and 12-year-old males, who may not have undergone sexual maturation. In line with previous reports ${ }^{(31,32)}$, we observed a null overall association of screen time with adiposity in female adolescents. However, we explored whether sexual maturity modified the associations by stratifying on menarcheal status and observed a significant increasing trend in SSF thickness in sexually immature females ( $P$ for interaction $=0.053$ ). SSF velocity and distance curves diverge markedly in males and females during maturation. Results of these post hoc analyses should be interpreted with caution. Nevertheless, given null findings in studies with older adolescents, the association of sedentary behaviour/ inactivity with measures of central fat distribution may be partially explained by maturity and different maturational tempos between males and females.

When we evaluated television and videos/video games independently, we did not find an association with anthropometric measures of adiposity and obesity. Nevertheless, videos and video games represent close to $50 \%$ of total screen time in this sample of Mexican adolescents. The association with measures of fat mass and distribution appeared to be driven by the combined effects of these three activities, underscoring the importance of measuring the use of all electronic media.

Mechanisms thought to underlie the relationship between screen time and adiposity are low energy expenditure due to the substitution of physical activity by television viewing and an increase in the consumption of energy-dense foods advertised on television. Recent data lend stronger support to energy intake as mediator of the effect of screen time on adiposity ${ }^{(36-38)}$. A reduction in television viewing and computer use was reported to significantly reduce daily energy intake by close to $300 \mathrm{kcal}(1255 \mathrm{~kJ})$ over two years, while no significant increase in physical activity was observed over the same period ${ }^{(11)}$.

In the current study, we evaluated the association of screen time and adiposity in a large sample of adolescents using measures of both fat mass (BMI) and central (SSF) and peripheral (TSF) fat distribution. We closely captured recreational inactivity by using a questionnaire validated in Mexican children ${ }^{(9)}$ that estimates time spent on television, video and video games on weekdays, Saturday and Sunday. Height, weight, TSF and SSF thickness were reliably measured with calibrated equipment by trained personnel using standardized procedures. SSF, a measure of central fat distribution, rarely has been available in population-based studies of this magnitude and our findings provide an interesting insight into its association with screen time during maturation. Consistency in results across different anthropometric measures with independent measurement errors may further support the presence of the associations found in the present report.

Our study has some limitations that temper interpretation of findings. First, causal inference is limited by the cross-sectional design of the study. We hypothesized that screen time was a determinant of increased adiposity, but we were unable to assess whether a reverse effect existed. Prior reports based on longitudinal data support the directionality of the observed association. Second, data on screen time and potential confounders are selfreported, creating a potential for recall bias. However, we believe that participants in this study population were unaware that screen time could be a cause of increased adiposity, so it is unlikely that obese or overweight adolescents would have reported screen time differently from their leaner counterparts. We are more concerned with the potential for inaccurate reporting that would attenuate of the associations. Third, our questionnaire did not include computer use. At the time the survey was conducted, the contribution of computer use to overall hours spent in front of a screen was probably very limited in this population. As in any observational study, our results may be explained by the influence of unmeasured confounders. However, we were able to reduce this possibility by adjusting for numerous socio-economic and lifestyle variables.

We conclude that screen time is associated with increased adiposity in Mexican adolescent males. The association may be partly influenced by maturation; screen time may be more important in younger adolescents and be more influential in determining central fat stores, as indicated by SSF. Our results underscore the importance of understanding modifiable determinants of adolescent obesity in the context of trends in Mexico. The high prevalence of obesity and overweight in adolescents may foreshadow an even greater surge in CVD and diabetes in Mexico as these adolescents enter young adulthood. Preventive interventions to promote physical activity and limit screen time have been explored in similar populations and were shown to be effective ${ }^{(39)}$. As seen in other populations ${ }^{(35)}$, a thorough evaluation of recommendations on physical activity and screen time in the Mexican context would be important to support public policy. Future research should focus on accurately assessing screen time and physical activity and their association with adiposity at the national level and on identifying culturally tailored strategies to modify these behaviours in Mexican youths.

\section{Acknowledgements}

M.L. was supported by the Mexican National Council for Science and Technology (CONACyT), the Ministry of 
Health of Mexico, the Cabot Family Charitable Trust and the Epidemiology Department at the Harvard School of Public Health (HSPH). J.C. was supported by the NIDDK training grant T32-DK07703 and the HSPH Yerby Postdoctoral Fellowship Program. The study was partly funded by Bristol-Myers Squibb Foundation of New York, under the initiative 'Better Health for Women: A Global Health Program'. Additional funding was provided by CONACyT grant number 34487-M and the National Institute of Public Health of Mexico (INSP). Elizabeth Devore participated in the initial data management. None of the authors had a personal or financial conflict of interest. Study design and data collection were performed by E.L.-P., M.H.-A., B.H.-P. and A.C.-V. E.L.-P was responsible for funding the study. Analysis plan and manuscript preparation were done by M.L., J.C., K.E.P. and B.H.-P.

\section{References}

1. James PT, Leach R, Kalamara E \& Shayeghi M (2001) The worldwide obesity epidemic. Obes Res 9, Suppl., 228S-233S.

2. Olaiz G, Rojas R, Barquera S, Shamah T, Aguilar C, Cravioto P, de la Paz López M, Hernández M, Tapia R \& Sepúlveda J (2000) Encuesta Nacional de Salud 2000. tomo 2: La salud de los adultos. Cuernavaca, México: Instituto Nacional de Salud Pública.

3. Olaiz-Fernández G, Rivera-Dommarco J, Shamah-Levy T, Rojas R, Villalpando-Hernández S, Hernández-Avila M \& Sepúlveda-Amor J (2006) Encuesta Nacional de Salud y Nutrición 2006. Cuernavaca, México: Instituto Nacional de Salud Pública.

4. Hernández B, Cuevas-Nasu L, Shamah-Levy T, Monterrubio EA, Ramírez-Silva CI, García-Feregrino R, Rivera JA \& Sepúlveda-Amor J (2003) Factors associated with overweight and obesity in Mexican school-age children: results from the National Nutrition Survey 1999. Salud Publica Mex 45, Suppl., s551-s557.

5. Gortmaker SL, Must A, Sobol AM, Peterson K, Colditz GA \& Dietz WH (1996) Television viewing as a cause of increasing obesity among children in the United States, 1986-1990. Arch Pediatr Adolesc Med 150, 356-362.

6. Proctor MH, Moore LL, Gao D, Cupples LA, Bradlee ML, Hood MY \& Ellison RC (2003) Television viewing and change in body fat from preschool to early adolescence: the Framingham Children's Study. Int J Obes Relat Metab Disord 27, 827-833.

7. Andersen RE, Crespo CJ, Bartlett SJ, Cheskin LJ \& Pratt M (1998) Relationship of physical activity and television watching with body weight and level of fatness among children: results from the Third National Health and Nutrition Examination Survey. JAMA 279, 938-942.

8. Berkey CS, Rockett HRH, Gillman MW \& Colditz GA (2003) One-year changes in activity and in inactivity among 10- to 15 -year old boys and girls: relationship to change in body mass index. Pediatrics 111, 836-842.

9. Hernández B, Gortmaker SL, Colditz GA, Peterson KE, Laird NM \& Parra-Cabrera S (1999) Association of obesity with physical activity, television programs and other forms of video viewing among children in Mexico City. Int J Obes Relat Metab Disord 23, 845-854.

10. Hancox RJ, Milne BJ \& Poulton R (2004) Association between child and adolescent television viewing and adult health: a longitudinal birth cohort study. Lancet 364, $257-262$.
11. Epstein LH, Roemmich JN, Robinson JL, Paluch RA, Winiewicz DD, Fuerch JH \& Robinson TN (2008) A randomized trial of the effects of reducing television viewing and computer use on body mass index in young children. Arch Pediatr Adolesc Med 162, 239-245.

12. Robinson TN (1999) Reducing children's television viewing to prevent obesity: a randomized controlled trial. JAMA 282, 1561-1567.

13. Gortmaker SL, Peterson KE, Wiecha JL, Sobol AM, Dixit S, Fox MK \& Laird N (1999) Reducing obesity via schoolbased interdisciplinary intervention among youth: Planet Health. Arch Pediatr Adolesc Med 153, 409-418.

14. Lazcano-Ponce EC, Hernández B, Cruz-Valdez A, Allen B, Díaz R, Hernández C, Anaya R \& Hernández-Avila M (2003) Chronic disease risk factors among healthy adolescents attending public schools in the State of Morelos, Mexico. Arch Med Res 34, 222-236.

15. National Center for Health Statistics (2008) 2000 CDC Growth Charts: United States. http://www.cdc.gov/growthcharts/ (accessed January 2009).

16. Must A, Dallal GE \& Dietz WH (1991) Reference data for obesity: 85th and 95th percentiles of body mass index (wt/ht) and triceps skinfold thickness. Am J Clin Nutr 53, 839-846.

17. Must A, Dallal GE \& Dietz WH (1991) Reference data for obesity: 85th and 95th percentiles of body mass index (wt/ $\mathrm{ht}^{2}$ ) and triceps skinfold thickness - a correction. Am J Clin Nutr 54, 773 .

18. Hernández B, Gortmaker SL, Laird NM, Colditz GA, ParraCabrera S \& Peterson KE (2000) Validity and reproducibility of a physical activity and inactivity questionnaire for Mexico City schoolchildren. Salud Publica Mex 42, 315-323.

19. Ainsworth BE, Haskell WL, Whitt MC et al. (2000) Compendium of physical activities: an update of activity codes and MET intensities. Med Sci Sports Exerc 32, Suppl., S498-S504.

20. Hernandez-Avila M, Romieu I, Parra S, Hernandez-Avila J, Madrigal H \& Willett W (1998) Validity and reproducibility of a food frequency questionnaire to assess dietary intake of women living in Mexico City. Salud Publica Mex 40, 133-140.

21. Bronfman M, Guiscafré H, Castro V, Castro R \& Gutiérrez G (1988) La metodologia y análisis de lãs características socieconómicas de la muestra. Arch Invest Med 19, 351-360.

22. Cole TJ, Bellizzi MC, Flegal KM \& Dietz WH (2000) Establishing a standard definition for child overweight and obesity worldwide: international survey. BMJ $\mathbf{3 2 0}$, $1240-1243$.

23. Gortmaker SL, Dietz WH Jr \& Cheung LW (1990) Inactivity, diet, and the fattening of America. J Am Diet Assoc 90, $1247-1252$.

24. Vandewater EA, Shim M \& Caplovitz AG (2004) Linking obesity and activity level with children's television and video game use. J Adolesc 27, 71-85.

25. Crespo CJ, Smit E, Troiano RP, Bartlett SJ, Macera CA \& Andersen RE (2001) Television watching, energy intake and obesity in US children: results from the Third National Health and Nutrition Examination Survey 1988-1994. Arch Pediatr Adolesc Med 155, 360-365.

26. Giammattei J, Blix G, Marshak $\mathrm{HH}$, Wollitzer AO \& Pettitt DJ (2003) Television watching and soft drink consumption: associations with obesity in 11- to 13 year old schoolchildren. Arch Pediatr Adolesc Med 157, 882-886.

27. Eisenmann JC, Bartee RT, Smith DT, Welk GJ \& Fu Q (2008) Combined influence of physical activity and television viewing on the risk of overweight in US youth. Int J Obes (Lond) 32, 613-618. 
28. Blair NJ, Thompson JM, Black PN, Becroft DM, Clark PM, Han DY, Robinson E, Waldie KE, Wild CJ \& Mitchell EA (2007) Risk factors for obesity in 7-year-old European children: the Auckland Birthweight Collaborative Study. Arch Dis Child 92, 866-871.

29. Gomez LF, Parra DC, Lobelo F, Samper B, Moreno J, Jacoby E, Lucumi DI, Matsudo S \& Borda C (2007) Television viewing and its association with overweight in Colombian children: results from the 2005 National Nutrition Survey: a cross sectional study. Int J Behav Nutr Phys Act 4, 41.

30. Mendoza JA, Zimmerman FJ \& Christakis DA (2007) Television viewing, computer use, obesity, and adiposity in US preschool children. Int J Behav Nutr Phys Act $\mathbf{4}$, 44.

31. Wolf AM, Gortmaker SL, Cheung L, Gray HM, Herzog DB \& Colditz GA (1993) Activity, inactivity, and obesity: racial, ethnic, and age differences among schoolgirls. Am J Public Health 83, 1625-1627.

32. Robinson TN, Hammer LD, Killen JD, Kraemer HC, Wilson DM, Hayward C \& Taylor CB (1993) Does television viewing increase obesity and reduce physical activity? Cross-sectional and longitudinal analyses among adolescent girls. Pediatrics 91, 273-280.

33. Patrick K, Norman GJ, Calfas KJ, Sallis JF, Zabinski MF, Rupp J \& Cella J (2004) Diet, physical activity, and sedentary behaviors as risk factors for overweight in adolescence. Arch Pediatr Adolesc Med 158, 385-390.
34. Burke V, Beilin LJ, Durkin K, Stritzke WG, Houghton S \& Cameron CA (2006) Television, computer use, physical activity, diet and fatness in Australian adolescents. Int $J$ Pediatr Obes 1, 248-255.

35. Laurson KR, Eisenmann JC, Welk GJ, Wickel EE, Gentile DA \& Walsh DA (2008) Combined influence of physical activity and screen time recommendations on childhood overweight. J Pediatr 153, 209-214.

36. Taveras EM, Sandora TJ, Shih MC, Ross-Degnan D, Goldmann DA \& Gillman MW (2006) The association of television and video viewing with fast food intake by preschool-age children. Obesity (Silver Spring) 14, 2034-2041.

37. Utter J, Scragg R \& Schaaf D (2006) Associations between television viewing and consumption of commonly advertised foods among New Zealand children and young adolescents. Public Health Nutr 9, 606-612.

38. Wiecha JL, Peterson KE, Ludwig DS, Kim J, Sobol A \& Gortmaker SL (2006) When children eat what they watch: impact of television viewing on dietary intake and body mass Index in youth. Arch Pediatr Adolesc Med 160, 426-442.

39. Kain J, Uauy R, Albala C, Vio F, Cerda R \& Leyton B (2004) School-based obesity prevention in Chilean primary school children: methodology and evaluation of a controlled study. Int J Obes Relat Metab Disord 28, 483-493. 